\title{
Long-term monitoring of bedload and debris flows in two small catchments of the Eastern Italian Alps
}

\author{
L. Mao ${ }^{1}$, M. Cavalli ${ }^{2}$, F. Comiti ${ }^{1}$, L. Marchi ${ }^{2}$ \& M. Arattano ${ }^{3}$ \\ ${ }^{1}$ Department of Land and Agroforest Environments, \\ University of Padova, Italy \\ ${ }^{2}$ CNR-IRPI-Research Institute for Hydrological and Geological Hazards \\ Prevention, Padova, Italy \\ ${ }^{3}$ CNR-IRPI-Research Institute for Hydrological and Geological Hazards \\ Prevention, Torino, Italy
}

\begin{abstract}
In this paper, results from experimental stations located in two streams of the Eastern Italian Alps are presented: the Rio Cordon $\left(5.0 \mathrm{~km}^{2}\right)$ and the Moscardo Torrent $\left(4.1 \mathrm{~km}^{2}\right)$. The former hosts a measuring station for water and sediment (both suspended and bedload) transport rates operating since 1986, whereas the latter was set up in 1989 to monitor debris-flow events. Differences in sediment dynamics between the two basins are quantitatively investigated by using a magnitude-frequency analysis that highlights the relatively low sediment supply of the Rio Cordon and the unlimited sediment availability in the Moscardo Torrent.

Keywords: debris flow, bedload transport, long-term monitoring, magnitudefrequency analysis.
\end{abstract}

\section{Introduction}

Sediment transport in steep, small $\left(<10 \mathrm{~km}^{2}\right)$ catchments of the Alps is often represented by both Newtonian (floods with suspended and bedload transport) and non-Newtonian (debris and mud flows) behaviour, passing through hyperconcentrated flood events, characterized by intermediate characteristics. Despite a significant diversity as to their transport mechanics, the monitoring activity of 
such impulsive, high-energy processes in remote areas poses problems that are similarly complex. Their short duration and relatively low frequency of occurrence require the implementation of robust and reliable systems for performing direct field observation in remote areas. Indeed, monitoring activities carried out through permanently installed devices are very costly. However, these experimental sites become of extreme value when long-term series of data are eventually produced, thus allowing statistically significant analysis and experience-based predictions. Experimental measuring stations thus represent precious tools for the scientific community as well as for the agencies dealing with torrent control and land use planning.

In the present paper, the long-term series on sediment volumes in two instrumented channels in the Eastern Italian Alps (Moscardo Torrent and Rio Cordon, featuring debris flow and bedload events respectively), will be comparatively analysed.

\section{Study basins and channels}

The Moscardo Torrent and the Rio Cordon (fig. 1) are two small headwaters of the Eastern Italian Alps. The main morphometric parameters of the two basins are listed in table 1. Their climatic conditions are typical of Alpine environments, with precipitation (annual average $1,100 \mathrm{~mm}$ in the Rio Cordon, $1660 \mathrm{~mm}$ in the Moscardo torrent) occurring mostly as snowfall from November to April and snowmelt-dominated runoff in May and June. Short-duration summer floods and floods occurring in early autumn represent an important contribution to the flow regime and to the annual sediment yield.

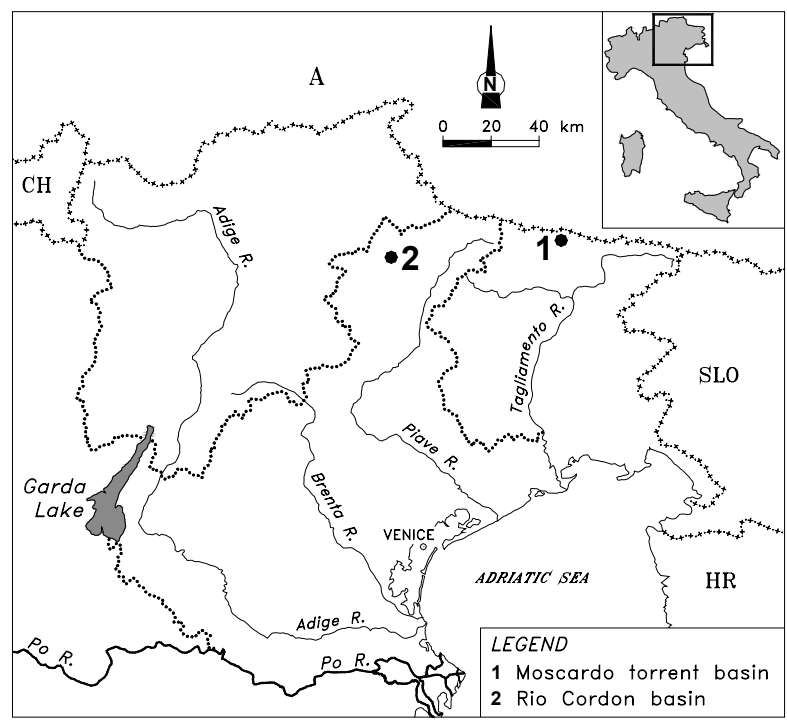

Figure 1: $\quad$ Location of Moscardo Torrent (1) and Rio Cordon (2). 
Table 1: Main characteristics of the Moscardo Torrent and Rio Cordon basins and channels.

\begin{tabular}{lcc}
\hline & Rio Cordon & Moscardo Torrent \\
\hline Basin area $\left(\mathrm{km}^{2}\right)$ & 5.0 & 4.1 \\
Minimum elevation (m.a.s.1.) & 1763 & 890 \\
Maximum elevation (m.a.s.l.) & 2748 & 2043 \\
Mean hillslopes gradient (\%) & 52 & 63 \\
Length of the main channel (km) & 2.84 & 2.76 \\
Mean gradient of the main channel (\%) & 13.6 & 37 \\
\hline
\end{tabular}

\subsection{Moscardo Torrent}

The Moscardo Torrent is a debris-flow channel belonging to the Tagliamento basin. The solid geology of the basin is composed of Carboniferous flysch, with highly fractured and weathered shale, slate, siltstone, sandstone and breccias. Quaternary deposits are common in the basin. The presence of a deep-seated gravitational deformation at the valley head, the low rock mass quality and its highly shattered state make the steep slopes of the basin prone to rockfalls and shallow landslides which supply large amounts of debris into the channel [9]. Vast sediment source areas are present in the upper part of the basin and along the main channel. The $64 \%$ and $18 \%$ of the basin area are covered by conifer forests and shrubs, respectively. Unvegetated areas, which occupy about $18 \%$ of the basin, provide most of the debris supplied to the channel network.

Typical debris-flow deposits (lateral levees) are present along the channel, whereas the frequent occurrence of debris flows prevents the formation of stable bedforms as step-pools (fig. 2). Concrete check dams were built in the main channel in order to limit bed erosion and to stabilise channel banks in the middle and lower reaches. The debris-flow deposits are poorly sorted and show a wide granulometrical distribution. Lateral levees and debris-flow lobes mostly consist of pebbles and medium to fine boulders supported in a muddy matrix; larger boulders with an intermediate diameter of 2-3 $\mathrm{m}$ are also common.

\subsection{Rio Cordon}

The Rio Cordon is a boulder-bed, step-pool stream draining an area of $5 \mathrm{~km}^{2}$. The hillslopes are very steep ( $52 \%$ as mean gradient) and, due to its high elevation, forests cover only the lower part of the catchment ( $7 \%$ of the area). Alpine grasslands dominate $(61 \%)$, but shrubs are relatively widespread too (18\%). $14 \%$ of the catchment area consists of bare land (scree and rocky cliffs). The solid geology mainly consists of dolomites, volcaniclastic conglomerates and tuff sandstones. Quaternary fluvioglacial and colluvial deposits are also very common. Active sediment sources, which are mainly represented by bare slopes, shallow landslides, eroded stream banks and minor debris-flow channels, cover a total area of $0.262 \mathrm{~km}^{2}$ (i.e., $5.2 \%$ of basin area). However, about $50 \%$ of the total sediment source area is located upstream of a low-gradient belt where 
sediment deposition takes place, thus making sediment supply from the upper part of the basin to be of minor relevance $[3,7]$.

The Rio Cordon mean channel slope is $13.6 \%$; the longitudinal channel profile displays an alternation of high-gradient and low-gradient stretches. The average bed surface grain size distribution is characterized (from grid-by-number pebble counts) by $\mathrm{D}_{50}=0.12$ and $\mathrm{D}_{84}=0.36$. The Rio Cordon is a boulder bed channel featuring a step-pool morphology (fig. 2), imparting a high stability to the bed channel for flood events with recurrence intervals (R.I.) lower than 30 40 years [5]. The grain size distribution of subsurface sediment is substantially finer than that relative to bed surface material, demonstrating a strong surface armouring.
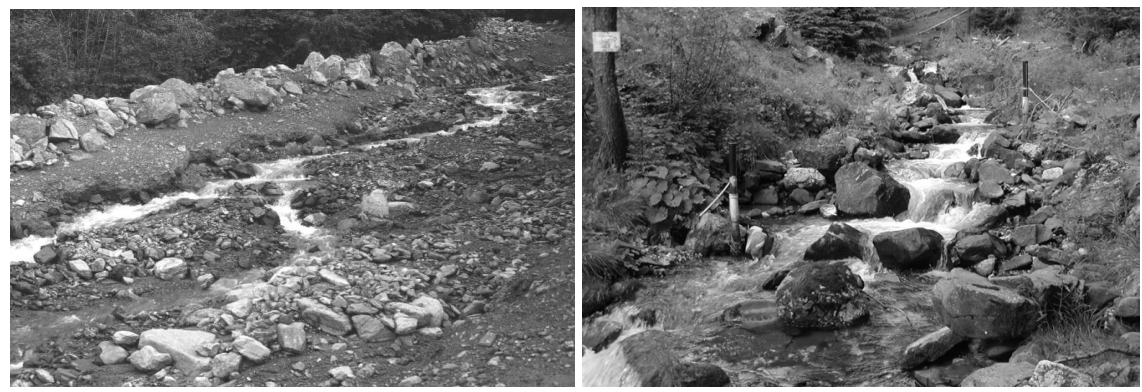

Figure 2: $\quad$ Pictures of the Moscardo Torrent (left) and the Rio Cordon (right) main channels.

\section{Monitoring devices}

\subsection{Moscardo Torrent}

In the Moscardo Torrent, a debris-flow monitoring system, designed and maintained by the Institute for Hydrological and Geological Protection of the Italian National Research Council (CNR IRPI), is operating since 1989. The Moscardo Torrent has appeared suited for the installation of such a system because it is characterised by frequent debris flows, by an easy accessibility and by a well-defined, stable channel on the fan, not subject to significant avulsions [9]. The installed instrumentation includes raingauges, ultrasonic sensors for the measurement of flow depth, seismic detectors for recording the vibrations caused by the passage of debris flows [1], and a video camera. The mean propagation velocity of the front is calculated as the ratio between the sensors (ultrasonic and/or seismic) distance and the time interval between the debris-flow peaks. The methods used for estimating peak discharge and flowing volume from ultrasonic records are discussed in Marchi et al. [9].

\subsection{Rio Cordon}

A station for monitoring water discharge, suspended sediment and bedload transport is operating since 1986 in the Rio Cordon [6, 7]. Measurements are 
taken by separating coarse grains (minimum size $20 \mathrm{~mm}$ ) from water and fine sediments. The measuring station consists of an inlet flume, an inclined grid where the separation of coarse particles takes place, a storage area for coarse sediment deposition, and an outlet flume to return water and fine sediment to the stream. The volume of bedload is measured at 5 -minute intervals by 24 ultrasonic sensors fitted on a fixed frame over the storage area [6,7]. Suspended sediment is measured by two turbidimeters: a Partech SDM-10 light absorption and a Hach SS6 light-scatter instrument. Flow samples are gathered automatically using a Sigma pumping sampler installed at a fixed position in the inlet channel. Data acquisition and instruments management are run by the Centro Valanghe of the ARPA Veneto.

\section{Recorded events}

\subsection{Moscardo Torrent}

In the Moscardo Torrent, from 1990 to 199815 debris-flow events occurred, 14 of which were recorded by the installed devices. Recorded debris flows range from small events, which would have probably remained undetected if a monitoring system had not been installed, to relatively intense phenomena, with volumes up to about $60,000 \mathrm{~m}^{3}$. The hydrographs recorded by the ultrasonic sensors show relevant differences from event to event. In particular, surge velocities and hydrograph shapes differ considerably. In some events, debris flows show a single, well-defined wave with a steep front followed by a continuous decrease in flow depth; a few smaller waves may follow the main surge; in other cases, the recession limb is very irregular with abrupt stage fluctuations [9]. There are features common to all recorded debris flows and these are the short duration of the event and the presence of a sharp rising limb in the hydrograph, corresponding to the passage of the debris flow front at the monitoring station.

\subsection{Rio Cordon}

The response time of such a small basin $\left(5 \mathrm{~km}^{2}\right)$ is very short, thus important flood events occur during intense, short-duration rainfall. Flood duration is accordingly brief, so that sediment transport lasts for a very limited time period (i.e., few hours per year). Overall, 23 bedload events were recorded by the Rio Cordon station from 1986 to 2004 [7]. During "ordinary" flood events, bedload showed intensity of up to $30 \mathrm{~kg} \mathrm{~s}^{-1}\left(4.6 \mathrm{~kg} \mathrm{~s}^{-1} \mathrm{~m}^{-1}\right)$, but most bedload rates range from 0.1 to $3 \mathrm{~kg} \mathrm{~s}^{-1}\left(0.03-0.6 \mathrm{~kg} \mathrm{~s}^{-1} \mathrm{~m}^{-1}\right)$. On $14^{\text {th }}$ September 1994, a flood presenting a peak water discharge of $10.4 \mathrm{~m}^{3} \mathrm{~s}^{-1}$ and a peak bedload transport rate of about $700 \mathrm{~kg} \mathrm{~s}^{-1}$ was recorded at the station [2]. Such a high-magnitude event features the typical flash-flood pattern, i.e. a very high peak flow rate, a very short duration (4 hours), and a large total bedload volume $\left(900 \mathrm{~m}^{3}\right)$. During its peak, the September 1994 flood approached conditions of hyper-concentrated flows. Indeed, a visual observation of the event (taped by a video camera) 
confirms that a hyper-concentrated flow was likely reached at a certain time. Given the steepness of some channel stretches, a further possible shift toward debris flows may be envisaged for higher-magnitude events with R.I. $>100$ years [7]. In fact, field evidences along the main channel and on adjacent terraces, such as lobes and levees with large boulders, suggest that debris flows could have occurred in the past.

\section{Magnitude-discharge and magnitude-duration relationships}

In figure 3, debris-flow magnitudes (volume in $\mathrm{m}^{3}$ ) registered in the Moscardo Torrent are plotted versus the associated peak discharges. In the same graph, the bedload volumes and peak flow rates measured at the Rio Cordon station are also plotted. Since the two catchments are of comparable size (tab. 1), the comparison was carried out without dividing magnitude and discharge values by basin area. Despite some differences in measured variables (peak discharge refers to the solid-liquid mixture in the Moscardo and only to the liquid fraction in the Cordon), a certain continuity is apparent between the two channels, even though the lack of overlap preclude any reliable assertion. Assuming a power relationship between peak discharge and event magnitude $\left(Q_{p}=a M^{b}\right)$, the coefficients and exponents are $a=0.004$ and $b=1.022$ for the Moscardo and $a=1.455$ and $b=0.228$ for the Cordon. The coefficients of determination $\left(R^{2}\right)$ are 0.85 and 0.58 , respectively. The values of $b$ and $R^{2}$ indicate, respectively, a much faster increase of peak discharge for increasing event magnitude and a closer correlation between these two variables in the Moscardo Torrent than in the Rio Cordon. From the graph, the difference in transported sediment volumes between the two basins also becomes evident. In fact, in the Rio Cordon only the September 1994 event reaches a magnitude comparable to those of the smallest debris flows registered in the Moscardo Torrent (around 1,000 $\mathrm{m}^{3}$ ).

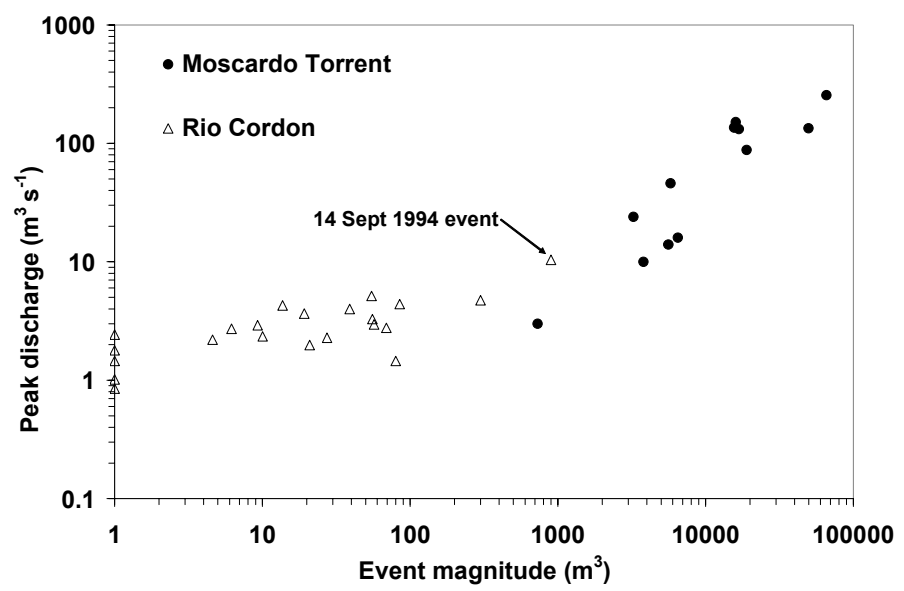

Figure 3: Magnitude versus peak discharges for the debris-flows events of the Moscardo Torrent and the bedload events of Rio Cordon. 
Along with peak discharge, a further important parameter affecting event magnitude is the duration of the event. In figure 4, event magnitude is plotted versus event duration for the two sites. Bedload events in Rio Cordon last longer (1 to 35 hours) than the flashy debris flows in the Moscardo Torrent $(<0.5$ hours), but the former discharged sediment volumes three orders of magnitude smaller than the latter. It could be noted that the limited variability of debris-flow duration in the Moscardo Torrent causes peak discharge to have a major role in explaining the variability of debris-flow magnitude (fig. 3). Even the Sept. 1994 flood in the Rio Cordon does not reach the magnitude/duration ratio showed by the Moscardo Torrent events. Interestingly for the Rio Cordon data, a marked difference between pre-1994 and post-1994 floods is clearly present, the latter featuring larger bedload volumes for similar transport durations (fig. 4(a)). This confirms that the 1994 flood removed the streambed armour layer, thereby increasing sediment supply for the subsequent events [7]. The pattern of the magnitude-duration relationships showed by the Rio Cordon also reveals seasonal differences. Snowmelt-induced floods are usually characterized by low peaks, long durations and low bedload transport magnitudes, plotting below the summer and autumn trends in figure 4(b). Summer and autumn floods, typically caused by intense rainfall, exhibits the highest magnitude-duration ratio.
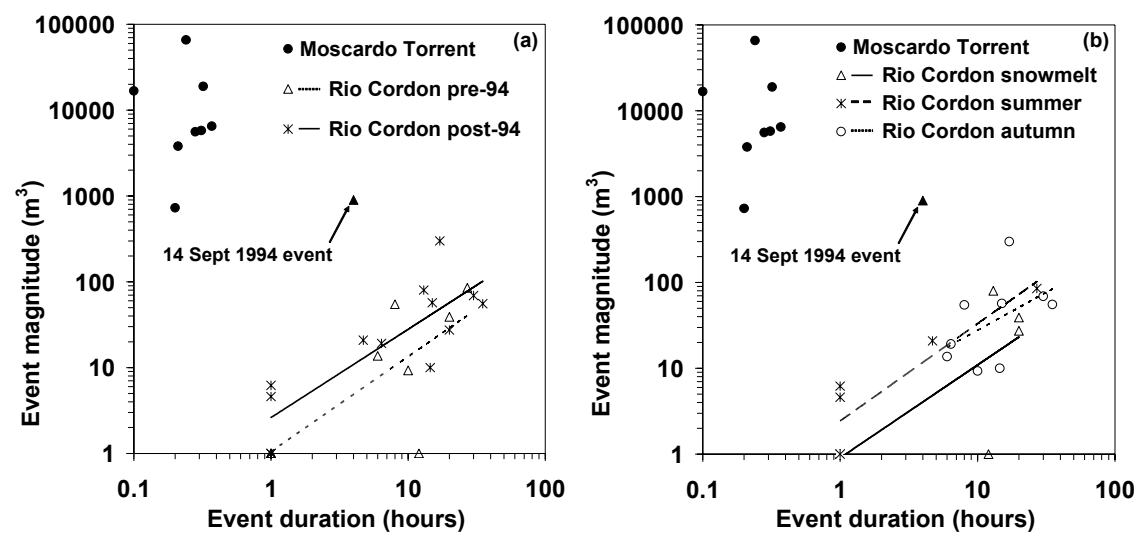

Figure 4: Magnitude - duration relationships for events measured both in the Moscardo and in the Cordon. Rio Cordon floods are grouped into pre- and post-Sept. 1994 events (a), and according to their season of occurrence (b).

Debris flows in the Moscardo Torrent take place in the summer months. Although total precipitation in autumn is often very abundant, no debris flows have occurred in October and November since the torrent was instrumented. This could be due to the infrequent occurrence of high-intensity storms during these months. Although huge amounts of loose debris are present on the slopes of the Moscardo basin, a temporary scarcity of sediment available for mobilisation in initiation zones after the occurrence of summer debris flows can also contribute to the absence of debris flows in autumn. The long-lasting, low to medium 
intensity, autumnal rainfall results in erosion and fluvial reworking of debris flow deposits accumulated in the middle and lower parts of the main channel, leading only to intense bedload transport [9].

\section{Magnitude-frequency analysis and sediment availability}

Magnitude-frequency analysis of debris-flow events greatly enhance our knowledge on these phenomena, leading to improve hazard assessment as well as the design of control measures $[4,10,11]$. The long-term sediment monitoring programme in two study channels allows to perform a statistical analysis of magnitude-frequency relations for both debris flows and bedload transport.

Marchi and D'Agostino [8] used the extreme value distribution EV1 to analyse the debris-flow magnitude-frequency relationship for the Moscardo Torrent and for other basins in the Eastern Italian Alps. In the Moscardo basin, where debris availability is nearly unlimited, debris flows occur almost each year and the magnitude of ordinary events (R.I. 5-10 yr) is about 50,000-60,000 $\mathrm{m}^{3}$.

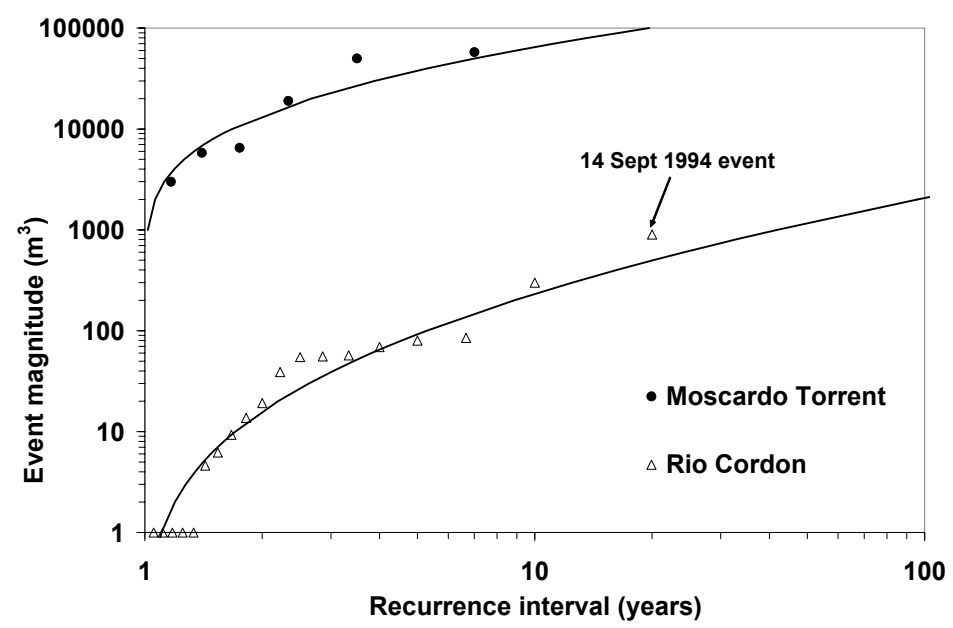

Figure 5: Magnitude-frequency relationships for the Moscardo and the Cordon. Empirical values (Weibull plotting position) are plotted with their lognormal equations.

In the Rio Cordon, using a log-normal distribution, Lenzi et al. [7] evaluated the peak discharge recurrence interval (R.I.) of each flood. Recurrence intervals of bed load volumes were also estimated considering the annual maximum volumes. Similarly to the peak water discharge analysis, the lognormal distribution was selected to calculate the frequency of occurrence of bed load volumes. The September 1994 event features a very high, infrequent peak flow rate $(R . I .=53 \mathrm{yr})$, with a total bed load volume of $900 \mathrm{~m}^{3}($ R.I. $>30 \mathrm{yr})$. This lowfrequency event deeply altered stream geometry [5] and sediment supply characteristics of the basin as a whole. The coarsest boulders $(\sim 1 \mathrm{~m})$ of the bed 
surface were entrained and transported to the station. Most sediment was supplied by the channel bed - the bed armour layer was removed - and channel banks, plus some point sources on the catchment slopes.

In figure 5, the magnitude-frequency relationships for the Moscardo Torrent and the Rio Cordon are shown. R.I. were estimated based on the maximum annual volume transported by a single event and adopting a lognormal distribution.

By comparing events' magnitude to their recurrence intervals (fig. 5), it clearly appears that sediment volumes transported as bed load by the Rio Cordon are decidedly lower than those mobilized as debris flows in the Moscardo Torrent. First of all, differences amongst the two studied basins regard mean slope and longitudinal profile of the channels. The Rio Cordon have a lower average slope than the Moscardo Torrent and displays an alternation of highgradient and low-gradient stretches. This stepped profile favours partial sediment deposition, so that debris flows could happen (for events with very high R.I.) only in some stretches of the channel. By contrast, although deposition of small debris flows within the basin has been observed in the Moscardo Torrent, high channel gradient and regular longitudinal profile, only slightly modified by the check dams built in the middle part of the channel, make it possible for most debris flows to reach the alluvial fan. Secondarily, sediment supply conditions differ considerably between the two basins, as already described in section 2. In the Rio Cordon, the generally limited sediment availability within the main channel can occasionally be - but with long-lasting effects in some cases increased either during low-frequency events (e.g. as the Sept. 1994 flood) able to remove the bed armour layer, or by sporadic mud flows and debris flows entering the main channel from the steeper tributaries [7]. On the contrary, in the Moscardo Torrent, widespread slope instabilities in the upper basin and along the main channel cause unlimited amounts of debris to be available, resulting in frequent debris flow events triggered also by relatively moderate rainstorms.

As a consequence of the dissimilar sediment dynamics between the two basins, the two main channels feature a different degree of bed structuring. In fact, the Rio Cordon displays well-developed step-pool sequences - exerting an important effect on flow energy dissipation and sediment routing - that are typical of supply-limited systems. Conversely, the Moscardo Torrent is characterized by a poorly-structured bed profile - only in part modified by the check dams built in its middle segment - that could be classified as "cascade". Such a bed morphology, typical of steep streams, likely derives from the frequent disturbances induced by the passage of debris flows and by the lack of sufficiently strong and persisting "clear" flows (i.e. carrying small sediment fractions) which would be needed to arrange clasts under a regular pattern such as the step-pool architecture.

\section{Conclusions}

The comparison of sediment transport data from the Moscardo Torrent and the Rio Cordon made it possible to outline some quantitative aspects of sediment 
dynamics in two small alpine basins of contrasting characteristics. The magnitude-frequency relations can be deemed representative of bedload channels with low to moderate sediment supply (Rio Cordon) and of debris-flow torrents with unlimited sediment availability (Moscardo Torrent). As it could be expected, the latter displays much higher magnitudes for comparable recurrence intervals. Long-term data series from more channels are highly desirable, because they could contribute to better define the magnitude-frequency relations for sediment transport in the headwaters of Alpine regions, and to associate typological characteristics of basins and channels (e.g. debris supply processes, topographic settings) with quantitative data relative to sediment yield.

\section{Acknowledgements}

Funding for this research was provided by the "Epic Force" Project EC INCOCT-2004-510735, from the MIUR project PRIN $2004 n^{\circ} 2004072251$ "Opere di riqualificazione ambientale dei corsi d'acqua: dalla scala di laboratorio a quella di campo", and from the University of Padova Project "Valutazione della pericolosità connessa a colate detritiche su conoidi alpini". Debris-flow monitoring in the Moscardo Torrent is part of the activities of the Geo-Risk Joint Lab, jointly established between Italy (CNR IRPI) and Japan (Public Work Research Institute).

\section{References}

[1] Arattano, M. On the use of seismic detectors as monitoring and warning systems for debris flows. Natural Hazards, 20(2-3), pp. 197-213, 1999.

[2] D'Agostino, V. \& Lenzi, M.A., Bedload transport in the instrumented catchment of the Rio Cordon: Part II. Analysis of the bedload rate. Catena, 36(3), pp. 191-204, 1999.

[3] Dalla Fontana, G. \& Marchi, L. Slope-area relationships and sediment dynamics in two alpine streams. Hydrological Processes, 17, pp. 73-87, 2003.

[4] Johnson, P.A., McCuen, R.H., \& Hromadka, T.V., Magnitude and frequency of debris flows. Journal of Hydrology, 123(1), pp. 69-82, 1990.

[5] Lenzi, M.A., Step-pool evolution in the Rio Cordon, north-eastern Italy. Earth Surface Processes and Landforms, 26, pp. 991-1008, 2001.

[6] Lenzi, M.A., D’Agostino, V., \& Billi, P., Bedload transport in the instrumented catchment of the Rio Cordon: Part I. Analysis of bedload records, conditions and threshold of bedload entrainment. Catena, 36(3), pp. 171-190, 1999.

[7] Lenzi, M.A., Mao, L. \& Comiti, F., Magnitude-frequency analysis of bed load data in an Alpine boulder bed stream. Water Resources Research, 40: W07201, doi:10.1029/2003WR002961, 2004.

[8] Marchi, L. \& D'Agostino, V., Estimation of debris-flow magnitude in the Eastern Italian Alps. Earth Surface Processes and Landforms, 29, pp. 207-220, 2004. 
[9] Marchi, L., Arattano, M. \& Deganutti, A.M., Ten years of debris-flow monitoring in the Moscardo Torrent (Italian Alps). Geomorphology, 46(1/2), pp. 1-17, 2002.

[10] Rickenmann, D., Empirical relationships for debris flows. Natural Hazards, 19, pp. 47-77, 1999.

[11] Zimmermann, M., Mani, P. \& Romang, H., Magnitude-frequency aspects of alpine debris flows. Eclogae Geologicae Helvetiae, 90(3) pp. 415-420, 1997. 